\title{
Lateral collision with side airbag: a literature review
}

\begin{abstract}
The paper presents a literature review of the efficacy of side passive safety in the event of lateral collision and the latest development of side airbag. According to the latest Global Status Report on Road Safety 2013, the total number of death every year due to road accident still maintained in a huge number of 1.24 million. Malaysia is one of the countries having highest estimated road traffic death rate of 25 per 100,000 populations. Moreover, 5\% growth annually of fatalities rate forecasted. In general, lateral collision or side impact is the second most common vehicle crash type which takes almost 10,000 occupant deaths each year. Side airbags were introduced into vehicle firstly in 1995 in order to improve occupants injury. It is statically proven that combination of head with thorax side airbag is very effective in reducing occupants fatalities rate, however thorax only airbag is less significant. With the aid from Computer Aided Engineer (CAE) software, designer can further improve airbag design and optimize its performance in order to find the best combination of design parameter such as of area of air vent, Time-To-Fire (TTF), operating pressure of the inflator gas and many more, while design cycle time can be reduced significantly up to $40 \%$. Nevertheless, people are afraid that side airbag deployment load may hurt children and small size female seated in Out-Of-Position (OOP). Researcher could resolve it by adopting the latest Computer Fluid Design (CFD) airbag simulation technique which have a better simulation result of OOP load, since CFD method provide more realistic airbag deployment simulations especially in the first few milliseconds which are significant in OOP test.
\end{abstract}

Keyword: Finite element analysis; Lateral collision; Out-of-position; Side airbag 